\title{
PENGARUH MOTIVASI KERJA, PELATIHAN DAN PENDIDIKAN TERHADAP KINERJA GURU DI SMK DWIJA DHARMA BOYOLALI
}

\author{
Cahyo Anggoro sakti ${ }^{1)}$, Dra. Nuning Lisdiana, $\mathrm{MM}^{2)}$, dan Dra.Listyowati PR,MM ${ }^{3)}$ \\ ${ }^{1)}$ Fakultas Ekonomi Universitas Boyolali \\ ${ }^{2)}$ Fakultas Ekonomi Universitas Boyolali \\ ${ }^{3)}$ Fakultas Ekonomi Universitas Boyolali \\ e-mail: Cahyoas6765@gmail.com ${ }^{1)}$, Nuninglisdiana60@gmail.com²), \\ Listyowatipujirahayu63@gmail.com ${ }^{3)}$
}

\begin{abstract}
ABSTRAK
Peneliti melakukan penelitian ini di SMK Dwija Dharma Boyolali dengan jumlah guru sebanyak 35 (tiga puluh lima) guru dan penelitian ini bertujuan untuk mengetahui bagaimana pengaruh variabel yang sesuai dengan judul terhadap kinerja guru di SMK Dwija Dharma Boyolali. Pneliti menggunakan metode Kuantitatif dengan teknik pengumpulan data melalui kuisoner. Dari hasil tes tersebut penelti mendapatakan hasil penelelitian yaitu menunjukan bahwa variabel peltihan dan pendikan berpengaruh positif terhadap kinerja guru di SMK Dwija Dharma Boyolali, variabel motivasi kerja secara parsial dan signifikan tidak mempengaruhi kinerja guru di SMK Dwija Dharma Boyolali. Pengaruh dari variabel-variabel tersebut mendapatkan hasil sebesar 45,9\% dan sisanya adalah factor-faktor lain yang tidak dimasukan dalam penelitian ini yaitu sebesakr 55,1\%
\end{abstract}

Kata kunci : Motivasi Kerja, Pelatihan Dan Pendidikan

\section{ABSTRACT}

Researchers conducted this research at SMK Dwija Dharma Boyolali with a total of 35 (thirty five) teachers and this study aims to determine how the influence of variables according to the title on teacher performance at SMK Dwija Dharma Boyolali in Boyolali. Researchers used quantitative methods with data collection techniques through questionnaires given and filled in by all teachers of SMK Dwija Dharma Boyolali without any coercion from any party. Researchers took all populations of 35 teachers as samples. This research uses several tests that the authors use. With the results of the test, the research obtained the results of the study, which showed that the training and education variables had a positive effect on the performance of teachers at SMK Dwija Dharma Boyolali, the work motivation variable partially and significantly did not affect the performance of teachers at SMK Dwija Dharma Boyolali. The effect of these variables got a result of $45.9 \%$ and the rest were other factors not included in this study, namely $55.1 \%$

Keywords: Work Motivation, Training And Education 


\section{Pendahuluan}

Guru adalah pahlawan tanpa tanda jasa memiliki tugas yang sangant mulia yaitu untuk mencerdaskan para penerus bangsa. Guru memiliki peranan yang sangat penting didalam proses kegiatan belajar mengajar di sekolah karena guru bisa mengetahhui perilaku muridnya. Jadi semua guru diwajibkan mempunyai kualitas mengajar dan pemahaman yang fundamental agar mampu mencetak siswa yang berkualitas dan mempunyai budi pekerti yang di harapakan bangsa. Peneliti melakukan penelitian ini untuk mengetahui apa sebenarnya penyebab kurang optimalnya kinerja guru di SMK Dwija Dharma Boyolali. Di dalam penelitian tersebut peneliti melakukan wawancara dan menyebar quesoner kepada semua guru di SMK Dwija Dharma Boyolali yang berisikan pertanyaan yang berkaitan dengan kinerja guru di SMK Dwija Dharma Boyolali.

\section{Landasan Teori dan Pengembangan Hipotesis}

\subsection{Pendidikan}

Menurut H. Fuad Ihsan (2005: 1) "menjelaskan bahwa dalam pengertian yang sederhana dan umum makna pendidikan sebagai Usaha manusia untuk menumbuhkan dan mengembangkan potensi-potensi pembawaan baik jasmani maupun rohani sesuai dengan nilai-nilai yang ada didalam masyarakat dan kebudayaan".

\subsection{Pelatihan}

Menurut Hamalik (2007:10) Pelatihan adalah "suatu proses yang meliputi serangkaian tindak (upaya) yang dilaksanakan dengan sengaja dalam bentuk pemberian bantuan kepada tenaga kerja yang dilakukan oleh tenaga profesional kepelatihan dalam satuan waktu yang bertujuan untuk meningkatkan kemampuan kerja peserta dalam bidang pekerjaan tertentu guna meningkatkan efektivitas dan produktivitas dalam suatu organisasi “

\subsection{Motivasi Kerja Guru}

Menurut Hasibuan (2010:92) Motivasi "berasal dari bahasa latin (Movere) yang berarti dorongan. Motivasi ini hanya diberikan kepada manusia, khususnya kepada para bawahan atau pengikut."

\subsection{Kinerja Guru}

Kinerja (prestasi kerja) adalah hasil kerja secara kualitas dan kuantitas yang dicapai oleh seseorang pegawai dalam melaksanakan tugasnya sesuai dengan tanggung jawab yang diberikan kepadanya. Mangkunegara (2016:)

\section{Metode Penelitian}

Penelitian ini adalah ppenelitian kuantitatif populasi penelitian ini adalah guru SMK Dwija Dahrma Boyolali sebnyak 35 guru, Penelitian ini mengambil semua populasi sebagai sampel karena populasi kurang dari 50 responden. 


\section{Hasil dan Pembahasan}

\subsection{Analisis Deskriptif Karakteristik Respoden Berdasarkan Usia}

Tabel 1

\begin{tabular}{|c|c|}
\hline Usia & $\begin{array}{c}\text { Guru SMK Dwija } \\
\text { Dharma Boyolali }\end{array}$ \\
\hline $26-30$ & 12 \\
\hline $31-40$ & 10 \\
\hline $41-65$ & 13 \\
\hline
\end{tabular}

Sumber primer, diolah tahun 2020

\section{Karakteristik responden menurut umur guru SMK Dwija Dharma Boyolali}

Berdasarkan tabel diatas dapat dijelaskan bahwa dari total 35 responden di penelitian ini terdapat 12 responden berumur 26-30 tahun, 10 responden berumur 31-40 tahun dan responden 13 berumur 41-65 tahun berjumlah 35 guru.

\subsection{Analisis Deskriptif Karakteristik Responden Berdasarkan Jenis Kelamin}

Tabel 2

\section{Berdasarkan Jenis Kelamin}

\begin{tabular}{|c|c|c|}
\hline Jenis Kelamin & Jumlah & Prosentase ( \% ) \\
\hline pria & 15 & $42 \%$ \\
\hline wanita & 20 & $58 \%$ \\
\hline Total & $\mathbf{3 5}$ & $\mathbf{1 0 0 \%}$ \\
\hline
\end{tabular}

Sumber primer, diolah tahun 2020

Dari Tabel 2 diatas diketahui bahwa jumlah 35 guru SMK Dwija Dharma yang di ambil untuk di jadikan responden, dominasi guru yang banyak adalah mereka yang berjenis kelamin wanita dengan jumlah 20 responden atau $70 \%$ untuk pria 15 responden dengan prosentase 30\% Ini menunjukkan bahwa guru SMK Dwija Dharma didominasi oleh guru perempuan. 


\subsection{Uji Validitas}

\subsubsection{Variabel Pendidikan (X1)}

Menunjukkan bahwa item-item pernyataan variabel pendidikan semua dinyatakan valid, karena $\mathrm{r}_{\text {hitungl }}>\mathrm{r}_{\text {tabel }}$. Skor tertinggi sebesar 0,734>0,282 ini yang kemudian bisa menunjukan bahwa setiap poin merupakan indikator untuk menjadi respon menegenai sebuah variabel pendidikan itu sendiri.

\subsubsection{Variabel Pelatihan (X2)}

Menunjukkan bahwa item-item pernyataan variabel semua dinyatakan valid,

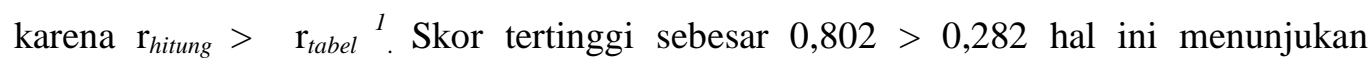
bahwasanya poin di atas iyalah indikator untuk bisa menjadikan respon. variabel Pelatihan ialah (Saya mendapatkan materi pelatihan sesuai dengan pekerjaan saya)

\subsubsection{Variabel Motivasi Kerja (X3)}

Menunjukkan bahwa item-item pernyataan variabel semua dinyatakan valid, karena $r_{\text {hitung }}>r_{\text {tabel }}$. Skor tertinggi sebesar 0,879>0,282 dengan demikian sesui itemitem yang di jelaskan menunjukan bahwasanya poin di atas merupakan sebuah indikator di mana dominannya menjadikan respon. variabel Motivasi Kerja ialah (Sejauh ini ketika Bapak atau Ibu bekerja apakah bapak ibu mendapatkan perlindungan)

\subsubsection{Kinerja Guru (Y)}

Menunjukkan bahwa item-item pernyataan variabel semua dinyatakan valid, karena $\mathrm{r}_{\text {hitung }}>\mathrm{r}_{\text {tabel }}{ }^{2}$. Skor tertinggi sebesar 0,875 > 0,282 menandakan bahwa butir tersebut adalah indikator yang dominan membentuk respon terhadap Kinerja Guru ialah (Dalam KBM, Bapak/Ibu guru menggunakan metode dan media pembelajaran yang sesuai dengan kompetensi yang diharapkan)

\subsection{Uji Reliabilitas}

Dalam uji ini diketahui bahwa item pernyataan dari pendidikan dengan nilai Cronbach Alpha 0.601, pelatihan dengan nilai Cronbach Alpha 0.695, motivasi kerja dengan nilai Cronbach Alpha 0.819 dan kinerja guru dengan nilai Cronbach Alpha 0.779 maka penelitian ini biasa dikatakan reliabel. Hal tersebut ditunjukan oleh nilai Cronbach Alpha >0,600. maka dari itu kuesioner yang telah dibuat dan diisi dapat dipercaya serta dapat dipakai untuk mendukung penelitian ini. 


\subsection{Analisis Data}

\subsubsection{Uji Asumsi Klasik}

\subsubsection{Uji Nrmalitas}

Diketahui bahwa setiap pernyataan dari variabel pendidikan, pelatihan, dan motivasi kerja dalam penelitian ini adalah berdistribusi normal ${ }^{3}$. Hal tersebut ditunjukan oleh nilai sig masing masing variabel $131>0,05$.

\subsubsection{Uji Multikolneritas}

Didalam uji ini Tidaklah ada multikolinearitas, namun ada hal uang di temukan yaitu bahwa adanya sebuah nilai tolerance yang lebihnya 0,1 sedangkan nilai dari VIF kurang dari $10^{4}$. Maka dengan demikian sebuah data yang di temukan pada penelitian saat ini tidak di temukannya multikolinearitas didalam variabel bebas dalam model regresi ${ }^{5}$.

\subsubsection{Uji Heterokedastisitas}

Tabel 3

\section{Coefficients $^{\mathrm{a}}$}

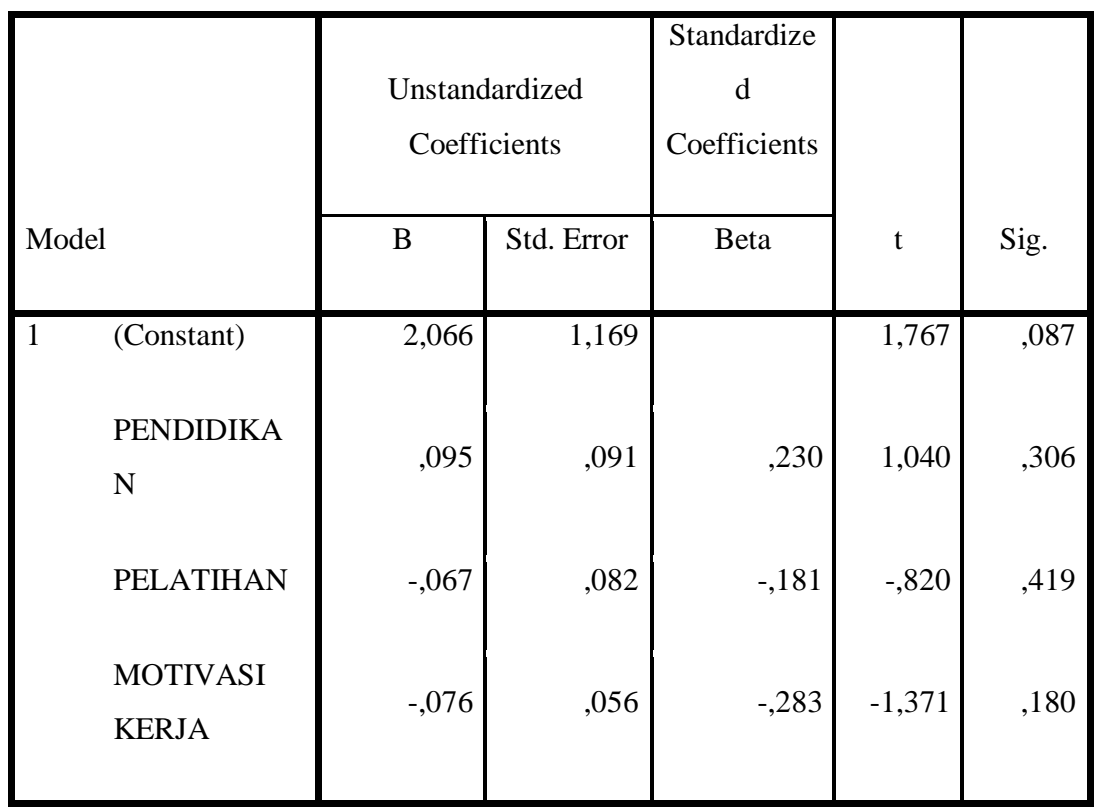

a. Dependent Variable: ABS_RES 
Dari hasil tampilan output Aplikasi SPSS 22 menunjukkan bahwa koefisien untuk variabel pendidikan variabel pelatihan dan variabel motivasi kerja mempunyai nilai lebih besar dari > 0.05 maka dapat disimpulkan bahwa model regresi dalam penelitian ini tidak ada heterokedastisitas ${ }^{6}$.

\subsubsection{Uji Autokorelasi}

\section{Tabel 4}

Model Summary

\begin{tabular}{|c|c|c|c|c|c|}
\hline $\begin{array}{c}\text { Mode } \\
1\end{array}$ & $\mathrm{R}$ & $\begin{array}{c}\mathrm{R} \\
\text { Square }\end{array}$ & $\begin{array}{c}\text { Adjusted R } \\
\text { Square }\end{array}$ & $\begin{array}{c}\text { Std. Error of } \\
\text { the Estimate }\end{array}$ & $\begin{array}{c}\text { Durbin- } \\
\text { Watson }\end{array}$ \\
\hline 1 &, $678^{\mathrm{a}}$ &, 459 &, 407 & 1,094 & 1,276 \\
\hline
\end{tabular}

a.Predictors:(Constant), MOTIVASI KERJA, PELATIHAN,

\section{PENDIDIKAN}

\section{b. Dependent Variable: KINERJA GURU}

Hasil analisis output aplikasi SPSS 22 tabel 4 diatas menunjukkan besarnya nilai Durbin Watson (DW) sebesar 1,276. Dengan jumlah variabel independen tiga $(\mathrm{k}=3)$ dan jumlah sampel $35(\mathrm{n}=35)$ diperoleh nilai dl sebesar 1,283 dan du sebesar $1,652^{7}$. Oleh karena nilai DW hitung 1,276> du 1,652, dan dengan menggunakan nilai signifikan 5\%, maka dapat disimpulkan tidak terjadi autokorelasi antar residual.

\subsection{Pengujian Hipotesis}

\subsubsection{Ujian $T$}

Pada sebuah variabel pendidikan, apabila Sig. $0,00>0,05$ maka $\mathrm{H}_{\mathrm{o}}$ diterima danH $_{\mathrm{a}}$ ditolak. Nilai Sig. 0.00 bahwasanya bahwa dalam penjelasan variabel pendidikan secara parsial sangat akan mempengaruhi cara kerja guru, dengan kata lain variabel pendidikan memiliki tingkat pengaruh yang sangat signifikan terhadap kinerja guru ${ }^{8}$.

\subsubsection{Uji F}

Dari hasil pengujian ini bahwa nilai Sig. $0,000<0,05$ hal ini menunjukkan bahwa semua variabel berpengaruh secara simultan. "penggunakan tingkat $\alpha$ (alfa) 
0,05 atau 5\% maka $\mathrm{H}_{\mathrm{o}}$ akan berhasil ditolak dan $\mathrm{H}_{\mathrm{a}}$ gagal ditolak. Penolakan $\mathrm{H}_{\mathrm{o}}$ dibuktikan dengan hasil perhitungan bahwa nilai Sig. $(0,000)<$ dari $\alpha($ alfa $)=0,05$ sehingga dapat disimpulkan bahwa semua variabel secara simultan mempengaruhi kinerja guru SMK Dwija Dharma di Kabupaten Boyolali”.

\section{Kesimpulan}

Setelah dilakukan peneletian denggan menyeber kuesoner kepada bapak/ibu guru SMK Dwija Dharma Boyolali sebagai responden kemudian data diperoleh diolah dengan menggunakan SPSS 22 maka diperolehasil dengan nilai koefisien determinasi $\left(\mathrm{R}^{2}\right)$ sebesar 0,459 memiliki artian bahwa Pndidikan, Platihan dan Motivasi Kerja berhubungan mampu mempengaruhi Kinerja Guru SMK Dwija Dharma Boyolali yang berjumlah 45,9\% dan sisanya adalah $55,1 \%$.

\section{DAFTAR PUSTAKA}

Alfhan, Rizalil, "PENGARUH PENDIDIKAN, PELATIHAN DAN MOTIVASI KERJA GURU TERHADAP KINERJA GURU EKONOMI AKUNTANSI SMA NEGERI DAN SWASTA SEKABUPATEN KENDAL", 2013

Mazidah, Nita Nur, 'Pengaruh Pelatihan Dan Motivasi Terhadap Kinerja Karyawan Dengan Disiplin Kerja Sebagai Variabel Intervening (Studi', Director, 15.April (2018), 2017-19 <https://doi.org/10.22201/fq.18708404e.2004.3.66178>

Muchlis, Imam, "Pengaruh Stres Kerja Terhadap Kinerja Karyawan Di Pt. Pengaruh Stres Kerja Terhadap Kinerja Karyawan Di Pt. Batik Danar Hadi Surakarta", Electronic Thesees and Dissertation.,12.1 (2015), 32-38 <https://doi.org/10.3923/ijss.2017.32.38>.

Rizkiyani, A H, and F Achmadi, 'STRATEGI PEMASARAN OBJEK WISATA DENGAN PENDEKATAN SERVQUAL MIXDAN QUALITY FUNCTION DEPLOYMENT (QFD) (STUDI KASUS DI OBJEK WISATA PANTAI TALANG SIRING KABUPATEN PAMEKASAN)', ... Teknologi XXIV Program Studi MMT-ITS, 2016 $<$ http://mmt.its.ac.id/download/SEMNAS/SEMNAS XXIV/MI/29. Prosiding Alifiana Hafidian Rizkiyani.pdf>

'Skripsi Universitas Mercu Buana'

SUGIONO, MASYRUUFAH, and SUCI ROHAYATI,"Pengaruh Penggunaan Bahan Ajar E-Book Interaktif, Pemahaman Analisis Transaksi Dan Intensitas Latihan Soal Terhadap Hasil Belajar Siswa Pada Materi Jurnal Khusus Akuntansi Perusahaan Dagang Kelas Xi Smk Negeri 2 Buduran Sidoarjo", Jurnal Pendidikan Akuntansi (JPAK), 5.3 (2017), 1-7

Sugiyono, Prof. Dr., "Pengaruh Motivasi Kerja, Disiplin Kerja Dan Kepuasan Kerja Terhadap Kinerja Karyawan Pada CV. Pangestu Percetakan Dan Desain Grafis Mojokerto", Journal of Chemical Information and Modeling, 53.9 (2016), 1689-99 <https://doi.org/10.1017/CBO9781107415324.004>

_ , 'Skripsi Universitas Malang', "Journal of Chemical Information and Modeling", 53.9 (2016), 1689-99 <https://doi.org/10.1017/CBO9781107415324.004>.

Wijayanti, Ratna Yulia, 'PENGARUH KEPEMIMPINAN, MOTIVASI, DAN KOMITMEN ORGANISASI TERHADAP KINERJA PNS DI LINGKUNGAN ORGANISASI DINAS PENDIDIKAN KABUPATEN KUDUS', Analisis Manajemen, 4.2 (2010), 136-52 